\title{
Verification of the deflection measurements method in the Lebanese soft rocky geo-material in excavation
}

\author{
Youssam Kazan \\ Lebanese University \\ Roumieh, Lebanon \\ youssamkazan@gmail.com
}

\begin{abstract}
In order to validate the design of retaining systems in deep excavation, measurements of site deformations become necessary. Usually, horizontal displacements are measured using inclinometers and vertical $6 \times 6 \mathrm{~cm}$ steel gains. These gains are often installed in the rigid or flexible vertical concrete element. In this case we consider that the displacement of soil is the displacement measured in this element. However, this assumption is to be reconsidered. The aim of this paper is to analyze the efficiency of this in situ method of measurement. We present qualitative comments on the measurements realized in three sides of a deep excavation in cohesive sandy soil in Lebanon. These measurements are performed using gains installed in vertical piles used for shoring and other gains installed freely in soil. The back analysis of the structure will show the influence of each method on the measurements. The influence of the friction between steel gain and the soil is calculated using the interface parameters in the calculation using finite element code.
\end{abstract}

Keywords-Measurement; displacement; calculation; validation; inclinometer.

\section{I.INTRODUCTION}

Various types of retaining systems, flexible or rigid, are used in deep excavations in such soils. However, the monitoring of these screen after excavations are rare, and it is almost impossible to find published values before the last decade [1]. The only criterion of validation of the method and parameters used in the calculation of these geotechnical structures is the stability of the excavation during execution work. Thus, retaining system, if they are recommended and executed, are often over designed.

In the last decade, several project were monitored in different soft rock (marl, cemented sand) and the corresponding cases history were published [2], [3] and [4]. Back analysis were done in order to verify engineering procedures and methods of design. Different conclusions were also formulated in order to rectify some points of view concerning the geo-material behavior and elastic parameters. All these works were based on the assumption that the experimental measurement of deflection are correct and represent exactly the behavior of the soil. Now it is time to discuss this mater closely.

The horizontal deflections are measured by the vertical inclinometers installed in the retaining system or in the soil using square metallic gains protected by grout injected in a borehole of about $15 \mathrm{~cm}$ diameter (see Fig.1).

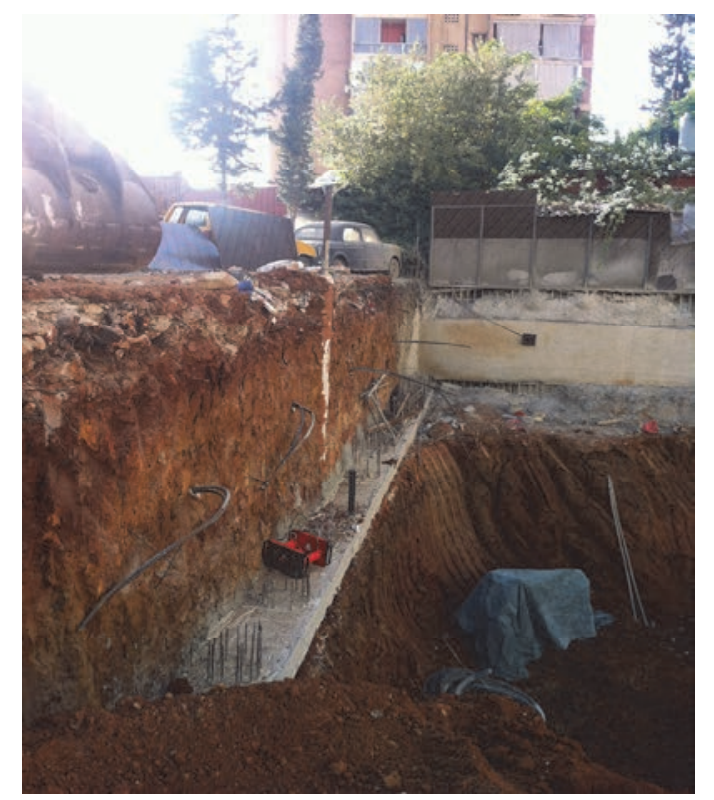

Fig. 1. Two inclinometers installed separately in side of excavation and in the pile retaining system

The Question now is: how to check and verify that the measured deflection corresponds exactly to the soil deflection? After a brief review of the general characteristics of the soft rocky cemented sand geo-material in Lebanon, we will present some measurement of one case history and procced by the specific analysis.

\section{General GeOlOGiCAL CONTEXT}

Cemented sandy soils are abundant in Lebanon. They are spread in almost fifty percent of coastal areas [5]. They are 
sometimes cemented by siliceous clay or by high concentration of calcareous contents. In this case, they are real $\phi$-c soils, and the cohesion has a big impact on the behavior of structures. The cohesion value is depending on water presence and conditions. It is very sensitive to thermal variation and altered easily whenever exposed to open air and meteoric change.

In some other cases, cemented sandy soils are noncemented, they are considered as classic frictional soils and they are not treated in this paper. These soils are usually compact and very dense, and sometimes gravelly. They are classified "very good" in most classification system. These soils may be loose; they will be treated as normal pure frictional sand. The characterization will be done in the standards of soil mechanics. In other cases these geological formations are highly cemented and rocky. Their characterization does not lead to confusion in applying the rock mechanics approaches. Sometimes they may have cavities [6], the treatment of this problem is beyond the scope of this paper.

However, the intermediate case, when cemented sand is within the limit of soft rock and hard soils, leads to some confusion [7]. In the geological context of Lebanon, the soil is formed by granular quartz in a fine matrix. The sampling becomes difficult and the results of in-situ tests will be widely dispersed. It is very difficult to obtain intact sample to use in laboratory tests devices and machines. The visual end laboratory examination of remained samples considered them as non-cohesive soil, and this is not realistic.

In the case history presented in this paper, we found in a single small project (and the same soil mass) both flexible and rigid retaining walls (anchored and not anchored). Compared with the measurements in huge project, these data may be considered not important; however there will be very interesting consideration of the comparative phenomena:

\section{CASE HISTORY IN WEAK SANDSTONE}

It is a fifteen stories building with two basements and a ground floor. The surface of the building excavation is approximately $800 \mathrm{~m}^{2}$. The plot is limited by road on the East side and another road on the partially west side (Fig.2). An adjacent building with one basement is located in the north east side.

The field has a trapezoid shape. The plot follows a very slight slope along the eastern direction. The foundation level of future construction is planned to eight meters deep.

\section{A. Geotechnical profile and parameters}

It is almost a homogenous soil. We do not consider in our analysis the thin top layer, a quaternary loose silty formation containing essentially limestone gravels (less than one meter thickness).

The soil is composed of two cemented sandy layers (Fig.3). The upper layer consists of red brown, medium plastic, fine silty sand with gravel with a depth of about $3 \mathrm{~m}$. The lower layer consists of a red brown, plastic, dense to very dense, fine clayey sand with gravel.

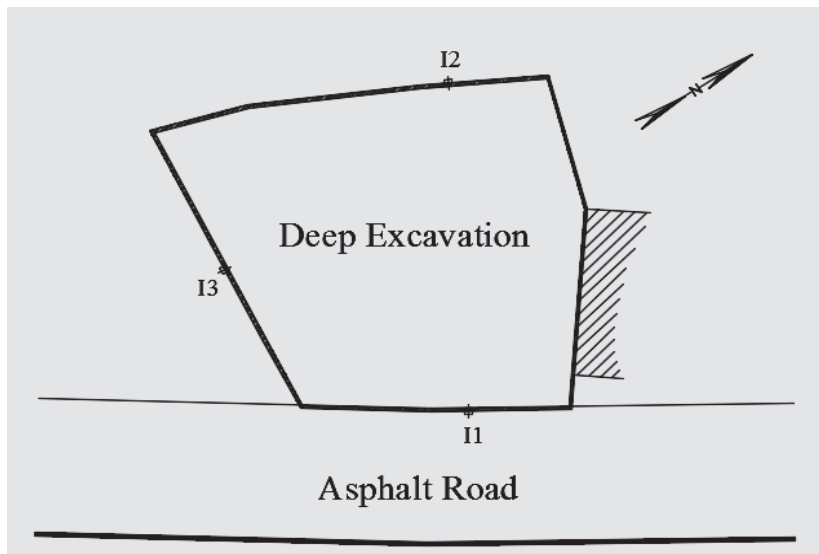

Fig. 2. Schematic plan of the excavation

During the site investigation works, the water table level was measured at 6 meters depth. However the excavation works were undertaken during the dry winter 2012-2013. The water level was below $11 \mathrm{~m}$ depth. It has no influence on the soil deformations.

Tests identifications and consistency, sieve analysis and Atterberg limits, were made on a selected samples to characterize the soil mass (or clayey) mentioned above. Results were accorded with the mechanical tests performed on ten samples. Interpretation of all these laboratory tests leads to propose the parameters in the following table.

TABLE I. MECHANICAL PARAMETERS OF BOTH LAYERS PROPOSED BY THE LABORATORY TESTS.

\begin{tabular}{|l|c|c|}
\hline \multicolumn{1}{|c|}{ Parameters } & Upper layer & Lower Layer \\
\hline Cohesion, c (KPa) & 10 & 15 \\
\hline $\begin{array}{l}\text { Angle of Internal Friction, } \phi \\
\text { degree }\end{array}$ & 32 & 30 \\
\hline Young's Modulus, E (MPa) & 10 & 25 \\
\hline $\begin{array}{l}\text { Unit weight of dry sample, } \gamma \\
\text { sec }(\mathrm{KN} / \mathrm{m} 3)\end{array}$ & 19 & 23 \\
\hline $\begin{array}{l}\text { Unit weight of saturated } \\
\text { sample, } \gamma \text { sat }(\mathrm{KN} / \mathrm{m} 3)\end{array}$ & 21 & \\
\hline
\end{tabular}

These proposed values for the mechanical parameters were considered smaller the real in-situ parameters as usually done in geotechnical practice in Lebanon (as described in paragraph 2). The Engineer decides to use the observational method in order to monitor the deformation of soil during excavation to optimize the cost of retaining systems.

\section{B. Flexible wall Deflection measurments}

The flexible retaining system in west site is a $15 \mathrm{~cm}$ thickness of shotcrete with one row of anchors of 15 tons spacing of $3 \mathrm{~m}$. the first curve was measured before execution of anchor. Displacement is similar to a free edge beam, with a total of $2 \mathrm{~mm}$. The anchor was installed and a new stage of construction was done until $7 \mathrm{~m}$ depth and the second curve was measured. The influence of anchor is clear. In this stage some passive nails were executed 3 to $4 \mathrm{~m}$ 
spaces. The third curve corresponds to the final stage of excavation.

One more curve was measured, three months after the final stage of excavation. We can clearly see additional deflections of about $2 \mathrm{~mm}$. These deformations may result from three different reasons:

- plasticity and creep behavior of soil

- relaxation of anchors and nails

- variation of the groundwater conditions

Modeling and interpretation of these phenomena must be undertaken carefully.

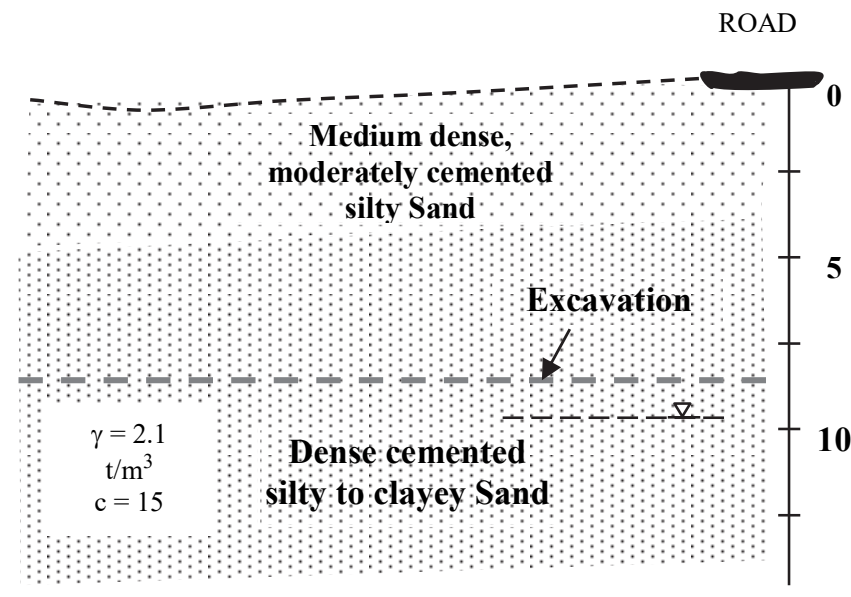

Fig. 3. Geological and geotechnical stratigraphy of the site

\section{Non anchored rigid wall}

For construction rules, the retaining system in the south side must be without anchors. He cannot propose flexible system as the west site, the engineer propose $\phi 60 \mathrm{~cm}$ outsidediameter spaced $1.5 \mathrm{~m}$. Excavation depth is about $8 \mathrm{~m}$ depth, the calculation design non admissible deflection. So the final solution was to execute the rigid piles after 3 or $4 \mathrm{~m}$ of free excavation as shown in Fig.1.

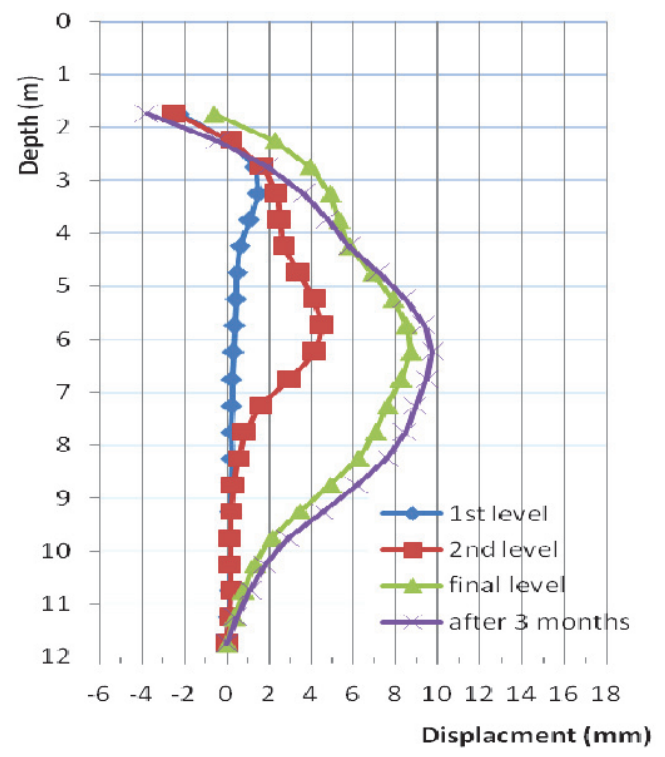

Fig. 4. Deflection of flexible retaining screen

This solution is acceptable because of cohesion in cemented sand. The total depth of piles was only $8 \mathrm{~m}$, four of them embedded under the excavation level. Interpretation of curves in Fig.5 shows that deflection in the upper free excavation (above $4 \mathrm{~m}$ depth) is clearly higher than deflection in the lower part of excavation.

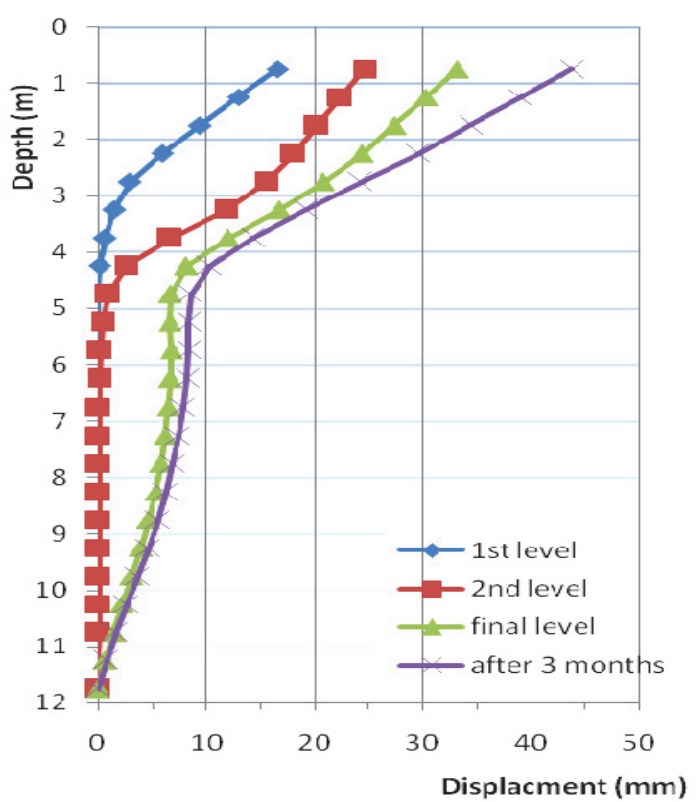

Fig. 5. Deflection of rigid retaining walls for non anchored rigid walls

Comparison between the two last curves shows the influence of non-elasticity in soil. The simulation studies should be focused on whether this phenomenon is due to the variation of water condition or viscosity in soil.

Only more significant deflection in the upper part is detected (about $10 \mathrm{~mm}$ ) after 3 months. The origin of this phenomenon may by the variation of the interface condition between soil and in inclinometer casing.

\section{INTERPRETATION AND VERIFICATION OF MEASURMENTS}

Engineers consider often than the vertical element in the retaining system (pile in our case) is submitted to horizontal load coming from the soil, depending of the area of influence for each element. If this logic is acceptable, what about the $15 \mathrm{~cm}$ diameter element in the free edge of the excavation?

Modelling by fine element (Plaxis 2D) of this element show the influence of interface condition in the upper free edge of excavation between the soil and the grout and metallic gain. Actually the depth of $4 \mathrm{~m}$ corresponds to the edge of the rigid part of retaining system. The deflection does not exceed one $\mathrm{cm}$. However, the measured value in the top is about $40 \mathrm{~mm}$.

It is clear the measured value of about $40 \mathrm{~mm}$ is due to the relative small value of interface coefficient $\mathrm{K}=0.25$. The real displacement of the soil is less than the measured value due to the cohesion of the soft rocky geo-material. 
Another way to check the validity of measurement is to use the difference finite method to deduce the bending moment in the vertical pile using the following equation (1):

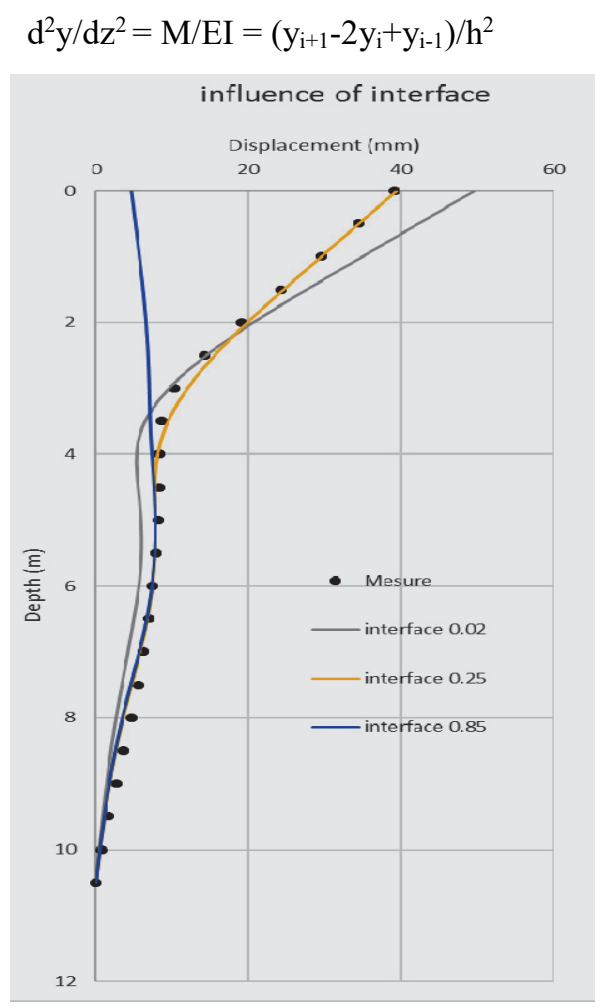

Fig. 6. Influence of interface on the horizontal deflection

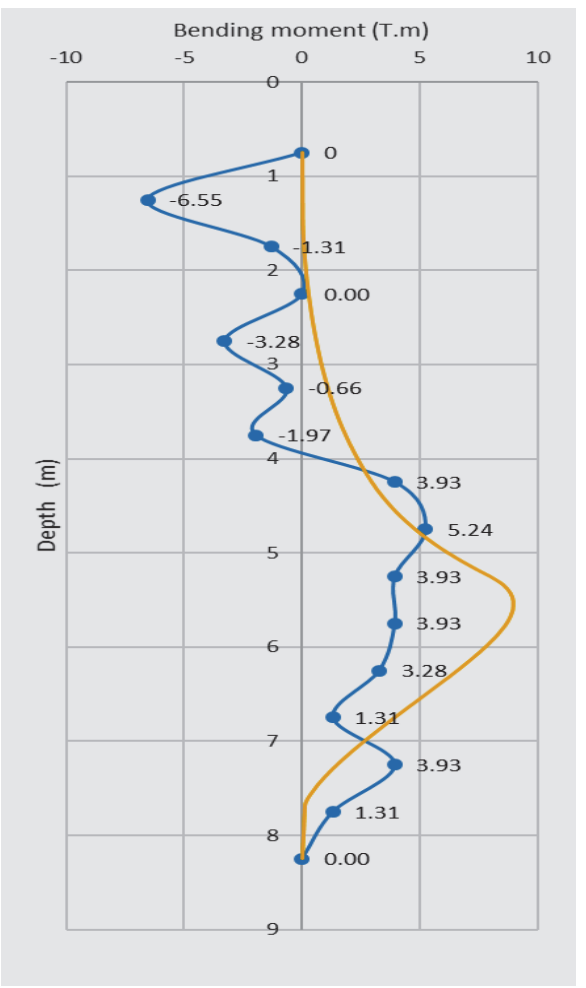

Fig. 7. Bending moment in the vertical pile: Comparison between values deduced from measurement and issued from structural calculation
The values of deflection, measured in a sequence of $\mathrm{h}=0.5 \mathrm{~m}$, cannot produce a smooth curve as to the calculated one. The qualitative interpretation of the Fig. 7 divides the opinion of engineers. Some of them call into question the validity of this method of measurement. Based on other point of view, some engineers consider that the shape of the curve is enough to accept these measurements and use them in the observational method used in design.

\section{CONCLUSIONS}

We discussed in this paper the procedure for the verification of the validity of in situ measurement of horizontal deflection of retaining systems in deep excavation in sandy soft rocky geo-material. We presented results of monitoring of different retaining systems (flexible and rigid, anchored and not anchored) in a small deep excavation.

We analyzed the influence of the condition of interface between soil and gain of inclinometer used for the measurements. We show the different points of view on the validity of this method of measurement at the point on the necessity to more analyze these results in such projects.

\section{REFERENCES}

[1] A. Fawaz et al., "Analyse inverse et modélisation d'essais pressiométriques réalisées sur un sol de Beyrouth," Revue Française de géotechnique, vol. 112, pp. 43-48, 2005.

[2] C. Saydi et al., " Monitoring, back analysis and redesign of a deep excavation retaining system in marl formation," MATEC web of conferences journal, proceeding of CMMS, 2013.

[3] Y. Kazan, "Modelling and redesign of retaining system of a deep excavation in marl formation using back analysis results," Proceedings of the ISRM European rock mechanics symposium, May 2014.

[4] A. Chour, "Monitoring and back analysis of retaining system deformation in sandy soils and sandstone," Interior report of Lebanese university, July 2014

[5] L. Dubertret, "Carte géologique du Liban: Revue de géographie de Lyon,” vol. 31(3), pp. 265-266, 1931.

[6] Y. Kazan, "Géologie du Liban vue par un géotechnicien," Revue Française de géotechnique," vol. 100, 2002.

[7] M. Khawlie et al., "Terrain analysis for development studies," Geological society of Hong Kong, bulletin no. 31987. 